\section{Editor-in-Chief \\ Barbara McLain - (retired Prof.) \\ University of Hawaii, USA}

The Israeli Journal of Aquaculture (IJA) is an interdisciplinary journal that is dedicated to sharing new research and tested applications of aquaculture

The IJA is devoted to scholarly articles for improved aquaculture practices and related industries

The IJA is a peer-reviewed, open-access, electronic journal

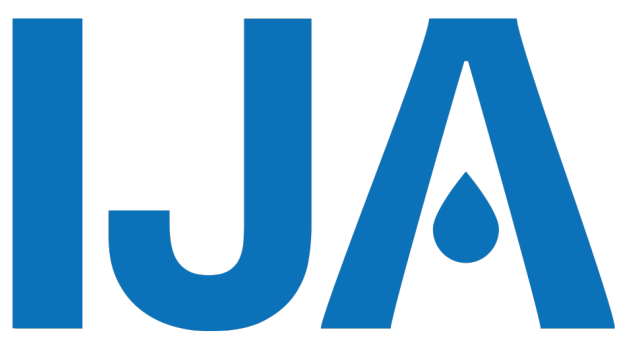

\section{The () Israeli Journal of Aquaculture}

An interdisciplinary online Open Access scientific journal

Published by the

\section{AquacultureHub}

A non-profit organization 501c3

http://www.aquaculturehub.org

in partnership with the

\section{University of Hawaii at Manoa} Library

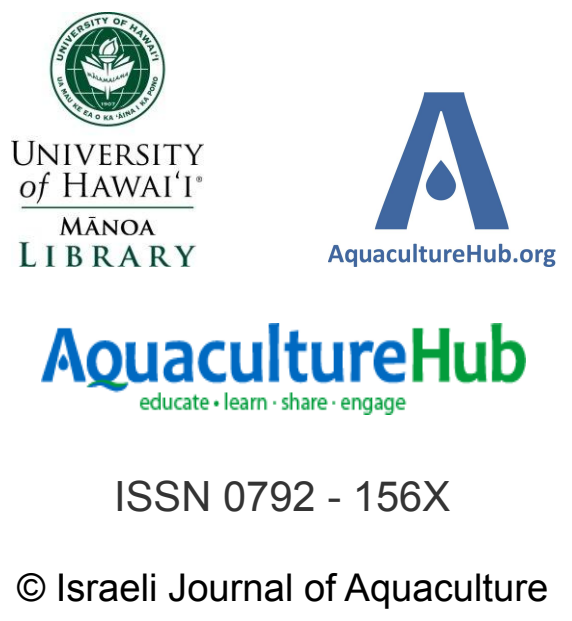




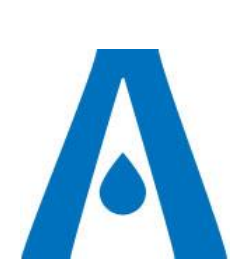

Produced by the AquacultureHub non-profit Foundation the IJA is an open-access, scientific journal, published on http://www.aquaculturehub.org/group/israelijournalofaq uaculturebamidgehija

To read papers free of charge, please register online at the above website.

Sale of IJA papers is strictly forbidden.

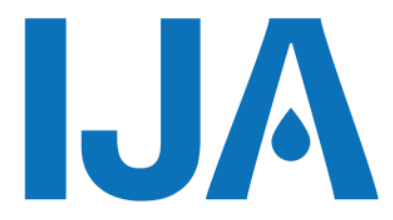

\title{
Effects of Different Salinities on Growth, Body Composition, Oxygen Consumption Rate, and Ammonia Excretion Rate in American shad (Alosa sapidissima) Juveniles
}

\author{
Chun Shui, Yinlong Yan, Yonghai Shi ${ }^{* 1}$, Jiabo $\mathrm{Xu}^{1}{ }^{1}$, Pingping Deng \\ Shanghai Fisheries Research Institute, Shanghai Fisheries Technical \\ Extension Station, Shanghai 200433, China
}

Keywords: salinity; American shad; growth; body composition; oxygen consumption rate; ammonia excretion rate

\begin{abstract}
A laboratory experiment was undertaken to analyze the effects of salinity on growth, body composition, oxygen consumption, and ammonia excretion of anadromous American shad (Alosa sapidissima) juveniles. Results showed the best survival rate occurred at $5 \%$ and $15 \%$. The relative weight gain and the specific growth rate declined as salinity increased. However, feed conversion rate increased with increasing salinity. Oxygen consumption rates showed a parabolic relationship in relation to salinity. From the quadratic relationship $\left(y=-0.0004 x^{2}+0.0166 x+0.319 ; R^{2}=0.801 ; P<0.05\right)$, the highest oxygen consumption rate occurred at a salinity of $20.75 \%$. The ammonia excretion ratio decreased significantly as salinity increased from $10 \%$ to $15 \%$. No further differences were observed in salinities ranging from $15 \%$ o to $40 \%$. There were no significant influences of salinity on whole body protein and moisture content. Lipid content declined as salinity increased. Results indicate that an appropriate increase in salinity was beneficial to the culture of American shad juveniles. The optimal salinity for American shad juveniles ranged from $15 \%$ o to $20 \%$.
\end{abstract}

\footnotetext{
* Corresponding author. Tel.: +86 21 57162574; fax: +86 21 57160897, email: yonghais@163.com (Y.Shi); shxujiabo@163.com (J.Xu)
} 


\section{Introduction}

Salinity changes markedly in natural waters. In freshwater rivers or lakes, salinity may be as low as $0.7 \%$, while in seawater it could be $33 \%$ or even above $50 \%$ (Gonzalez 2012). Environmental salinity is an important ecological factor due to its effects on physiology of aquatic organisms, for instance, growth can be influenced directly and distinctly. A considerable amount of literature had demonstrated the effects of salinity on growth: flounder Platichthys flesus, (Andersen et al. 2010), gilthead sea bream Sparus auratus, (Laizcarrion et al. 2006), and gray snapper Lutjnus griseus, (Wuenschel et al. 2005). Salinity has been reported to affect growth by changing the energy expenditure in fish to maintain the osmotic balance (Boeuf and Payan, 2001). Knowing species-specific salinity tolerances is useful for maximizing growth rates. Furthermore, there is underlying interest in determining the optimum salinity for each cultured species in a system where salinity can be altered artificially.

Oxygen consumption can be used to determine the energetic cost of osmoregulation via measurement of oxygen consumption rates in different salinities (Sparks et al. 2004). However, studies on the effect of salinity on oxygen consumption are ambiguous in relation to the increase (Chang et al. 2007), decrease (Swanson 1998), and constant oxygen consumption in relation to elevated salinity (Plaut 2000). Besides the energetic costs involved, the excretion of ammonia, products of protein metabolism, are also impacted by salinity. Data from several research studies has revealed a variety of different results in ammonia excretion rates as salinities increased. These include unchanged excretion rates (Pérez-Robles et al. 2012), decreased excretion rates (GraciaLopez et al. 2006), and increased excretion rates (Uliano et al. 2010), therefore there is no definite conclusion on these issues.

American shad Alosa sapidissima is one of the most abundant anadromous fish in the United States. It is widely distributed along the Atlantic coast of North America (Hasselman et al. 2013). American shad spend most of their lifetime in the sea but migrate to rivers to spawn. During migration, the American shad goes through marked salinity gradients. Surveys such as that conducted by Chittenden (1973) and Limburg and Ross (1995) documented the effects of salinity on American shad. In the early $21^{\text {st }}$ century, the American shad was introduced into China as a substitute of the nearly extinct Chinese shad Tenualosa reevesii. Many attempts have been made to elucidate their biology, such as early development (Gao et al. 2017; Hong et al. 2013), and gene expression ( $\mathrm{Bi}$ and Chen 2011). However, there is scarce information on the metabolism of American shad, with regard to salinity. It is crucially important to understand the metabolic changes in response to salinity. The purposes of this investigation were: 1) to assess the effects of salinity on growth and body composition; 2) to evaluate the salinityinduced changes in oxygen consumption and ammonia excretion. It is our hope that the results presented here will provide valuable information for American shad aquaculture in China.

Fish and rearing conditions

\section{Materials and Methods}

American shad juveniles (mean wet weight $\pm S D, 3.16 \pm 0.75 \mathrm{~g}, \mathrm{n}=50$ ) were obtained from the Shanghai Fisheries Research Institute (Shanghai, China), and stocked in 36 tanks (150L/tank), at a stocking density of 40 fish/tank. Fish were exposed to nine salinities [0\%o (control group), 5\%o, 10\%o, 15\%o, 20\%o, 25\%o, 30\%o, 35\%o, and $40 \%$ o]. Fish were exposed to each salinity treatment in independent recirculating water systems with 4 replicates per treatment. Changes in salinity were induced at a rate of less than $5 \%$ per day until reaching salinity of $40 \%$. Low salinity media was obtained by diluting sea water (10\%o) with fresh tap water; while in treatments above $10 \%$, ocean salts were added. Salinity was adjusted and measured by a hand-held salinity meter (YSI 30-10, Yellow Spring Instruments, Yellow Springs, OH, USA). Water exchange rate was $75 \%$ every other day by adding clean water of the same salinity in each treatment. All the replicates were tested every day to insure their respective constant salinity. Fish were fed commercial extruded feed (crude protein $\geq 45 \%$, crude lipid $\geq 6 \%$ ) and fed to apparent satiation twice a day (morning and afternoon). Feeding ceased when fish stopped eating. Uneaten feed was removed and counted by numbering the particles. 
The number of grains per gram of feed and the weight of single grain were calculated by weighing, and then the uneaten feed weight was obtained according to the number of remaining feed particles. Daily feed consumption was recorded for each replicate to calculate feed intake. All treatments were maintained at their respective salinity for 40 days.

Tissue sampling and metabolism determination

At the end of experiment, all fish were fasted for 24 hours, and each individual weight was obtained by weighing. Survival rates were determined by counting individuals remaining in each tank. Ten fish were selected at random from each tank to analyze their whole-body composition. The ten juveniles were slaughtered manually, and visceral mass was excised from the body. The bodies of the juveniles were then gently rinsed with distilled water, drained by filter paper and cut into pieces less than $0.5 \mathrm{~cm}$. Body samples were stored in a refrigerator at $-20^{\circ} \mathrm{C}$.

Moisture, crude protein, crude lipid, and ash content were analyzed. Moisture was measured by freeze-drying (freezer dryer, SIM FD5-3). Crude protein concentration was measured by an Automatic Kjeldahl System ( 8400 Auto analyzer; Foss Tecator AB, Hoganas, Sweden). Crude lipid was evaluated by chloroform/methanol $(2: 1, \mathrm{v} / \mathrm{v})$. Ash was calculated after combustion at $550^{\circ} \mathrm{C}$ in a muffle furnace.

Oxygen consumption rate was measured in a respirometer chamber according to Urbina and Glover (2015). After 40 days acclimation to the experimental salinities, three fish in each tank were selected and placed in a glass respirometer to determine the oxygen consumption rates. The chambers were placed in a water bath to maintain constant temperature. Each salinity group was held in four respiration chambers; three respiration chambers held juveniles, another respiration chamber with no juvenile was used in each group as a control. In order to minimize the possible influence caused by oxygen saturation, each measurement lasted 1-2 $\mathrm{h}$ until oxygen saturation reached about $60 \%$ (Shi et al. 2010). All measurement times were estimated according to different salinities by previous experiments aiming to ensure about $60 \%$ oxygen saturation at the end of each measurement. Before taking measurements, seawater was fully aerated for at least $2 \mathrm{~h}$ in a $150 \mathrm{~L}$ tank before filling the experimental chamber to assure oxygen saturation. Oxygen concentration was quantified at the beginning and end of the measurement by sampling water and determining oxygen content with an YSI-58 oximeter (Yellow Spring Instruments, Yellow Springs, OH, USA).

Ammonia excretion rates were determined by sampling water at the beginning and end of the oxygen consumption measurement and quantified by the indophenol method described by Ivančič et al. (1984).

Data calculation and statistical analysis

Growth performance was calculated as follows:

Survival $(\%)=100 \times$ number of shad surviving at the end of each tank/the number stocked initially of each tank

Relative weight gain $(\%)=100 \times[$ final mean body weight(g)-initial mean body weight $(\mathrm{g})] /$ initial mean body weight( $g$ )

Feed conversion rate $=$ total dry feed intake $(\mathrm{g}) /$ total wet weight gain $(\mathrm{g})$

Specific growth rate $(\% / d)=100 \times \ln [$ final mean body weight $(g)]-\ln [$ initial mean body weight(g)]/days

The oxygen consumption rate (OCR) and ammonia excretion rate were calculated based on the equations of Cerezo et al. 2006; Wright et al. 1995:

$\mathrm{OCR}=\left(C_{t}-C_{0}\right) V /(W \times T)$

$\mathrm{AER}=\left(C_{t 1}-C_{01}\right) V /(W \times T)$

Where $C_{t}$ and $C_{t 1}$ are the changes in oxygen $\left(\mathrm{mg} \mathrm{O}_{2} / \mathrm{L}\right)$ and ammonia $\left(\mathrm{mg} \mathrm{NH}_{4}^{+} / \mathrm{L}\right)$ concentration in the chambers during the experiment, and $C_{0}, C_{01}$ are the changes in oxygen ( $\mathrm{mg} \mathrm{O}_{2} / \mathrm{L}$ ) and ammonia $\left(\mathrm{mg} \mathrm{NH}_{4}^{+} / \mathrm{L}\right)$ content in the blank chambers in the period of incubation. $V$ is the volume of the chamber $(\mathrm{L}), \mathrm{W}$ is the body weight of the juvenile shad $(\mathrm{g})$, and $\mathrm{T}$ is the time of incubation in hours.

Statistical analyses were performed by SPSS 17.0 (SPSS Inc., Chicago, IL, USA). To determine the effect of salinity on growth, body composition, oxygen consumption, and ammonium excretion, a one-way analysis of variance was applied following Duncan's 
multiple tests to evaluate the differences among treatments. Significance level was set at $P<0.05$.

Survival and growth performance

\section{Results}

As shown in table 1, salinity significantly affected the growth performance of shad. After 40 days the lowest survival rate was at $40 \%$ o $(P<0.05)$, survival rates at salinities that ranged from $5 \%$ o to $30 \%$ showed no significant differences $(P>0.05)$ but were significant $(P<0.05)$ at higher than at $0 \%$. Relative weight gain declined as salinity increased. Relative weight gain at $0 \%$ was significantly higher $(P<0.05)$ than at $25 \%$, 30\%o, $35 \%$, and $40 \%$. There were no significant differences among the other four salinities, $25 \%$ o to $40 \%$ o $(P>0.05)$. Relative weight gain and specific growth rate decreased in relation to salinity increase. There was no significant difference in growth between the $0 \%$ and $5 \%$ groups $(P>0.05)$, but the results of these two groups were significantly higher than the $35 \%$ and $40 \%$ groups $(P<0.05)$. Specific growth rate showed no significant changes at salinities ranging from $10 \%$ o to $40 \%$ o $(P>0.05)$. In contrast to the relative weight gain and specific growth rate, feed conversion rate increased as salinity increasing. The value detected at $0 \%$ was 1.07 , significantly lower $(P<0.05)$ than in the $40 \%$ group (1.87). The feed conversion rates in the salinity ranging from $5 \%$ o to $35 \%$ o showed no significant differences $(P>0.05)$.

Table 1 Growth performance of the American shad A. sapidissima reared at different salinities

\begin{tabular}{lllll}
\hline Treatment & Survival $(\%)$ & Relative weight gain $(\%)$ & Specific growth rate $(\% / d)$ & Feed conversion rate \\
\hline 0 & $68.13 \pm 5.14^{\mathrm{x}}$ & $116.58 \pm 14.61^{\mathrm{z}}$ & $1.93 \pm 0.17^{\mathrm{z}}$ & $1.07 \pm 0.23^{\mathrm{x}}$ \\
5 & $95.63 \pm 4.27^{\mathrm{z}}$ & $104.64 \pm 12.19^{\mathrm{yz}}$ & $1.79 \pm 0.15^{\mathrm{yz}}$ & $1.31 \pm 0.13^{\mathrm{xy}}$ \\
10 & $87.50 \pm 5.40^{\mathrm{yz}}$ & $99.13 \pm 10.55^{\mathrm{xyz}}$ & $1.72 \pm 0.14^{\mathrm{xyz}}$ & $1.37 \pm 0.11^{\mathrm{xy}}$ \\
15 & $93.75 \pm 4.33^{\mathrm{yz}}$ & $94.62 \pm 6.89^{\mathrm{xyz}}$ & $1.66 \pm 0.09^{\mathrm{xyz}}$ & $1.31 \pm 0.12^{\mathrm{xy}}$ \\
20 & $89.37 \pm 4.27^{\mathrm{yz}}$ & $89.18 \pm 5.20^{\mathrm{xyz}}$ & $1.59 \pm 0.07^{\mathrm{xyz}}$ & $1.39 \pm 0.15^{\mathrm{xy}}$ \\
25 & $83.75 \pm 7.77^{\mathrm{y}}$ & $79.92 \pm 7.80^{\mathrm{yy}}$ & $1.46 \pm 0.21^{\mathrm{xy}}$ & $1.68 \pm 0.28^{\mathrm{yz}}$ \\
30 & $86.88 \pm 5.15^{\mathrm{yz}}$ & $79.71 \pm 8.93^{\mathrm{xy}}$ & $1.46 \pm 0.13^{\mathrm{xy}}$ & $1.45 \pm 0.17^{\mathrm{xy}}$ \\
35 & $85.00 \pm 7.36^{\mathrm{yz}}$ & $72.65 \pm 7.42^{\mathrm{x}}$ & $1.36 \pm 0.22^{\mathrm{x}}$ & $1.56 \pm 0.13^{\mathrm{yz}}$ \\
40 & $62.50 \pm 8.89^{\mathrm{x}}$ & $73.95 \pm 12.21^{\mathrm{x}}$ & $1.37 \pm 0.33^{\mathrm{x}}$ & $1.87 \pm 0.37^{\mathrm{z}}$ \\
\hline
\end{tabular}

Mean values (mean \pm S.D) are from four replicates of the shad under each salinity treatment. Values in a column share the same superscript are not significantly different $(P>0.05)$, similarly hereinafter.

Oxygen consumption rate and ammonia excretion rate

The oxygen concentration in the chambers did not drop to $60 \%$ saturation before and after the incubation. Oxygen consumption rate in the $0 \%$ group was $0.34 \mathrm{mg} \mathrm{O} / \mathrm{h} / \mathrm{g}$, which was significantly lower $(P<0.05)$ than in the $15 \%$ o, $20 \%, 25 \%$, 30\%o, and $35 \%$ o groups. There was no statistical difference $(P>0.05)$ among the other five salinities $15 \%$, 20\%o, 25\%o, 30\%o, and 35\%o. (Fig. 1).

Fig. 1 The effect of salinity on shad A) oxygen consumption rate (OCR), regression analysis defined the relationship between salinity and the oxygen consumption rate of the American shad (Alosa sapidissima); B) ammonia excretion rate (AER). Same letters of each bar indicate no significant differences $(P>0.05)$.
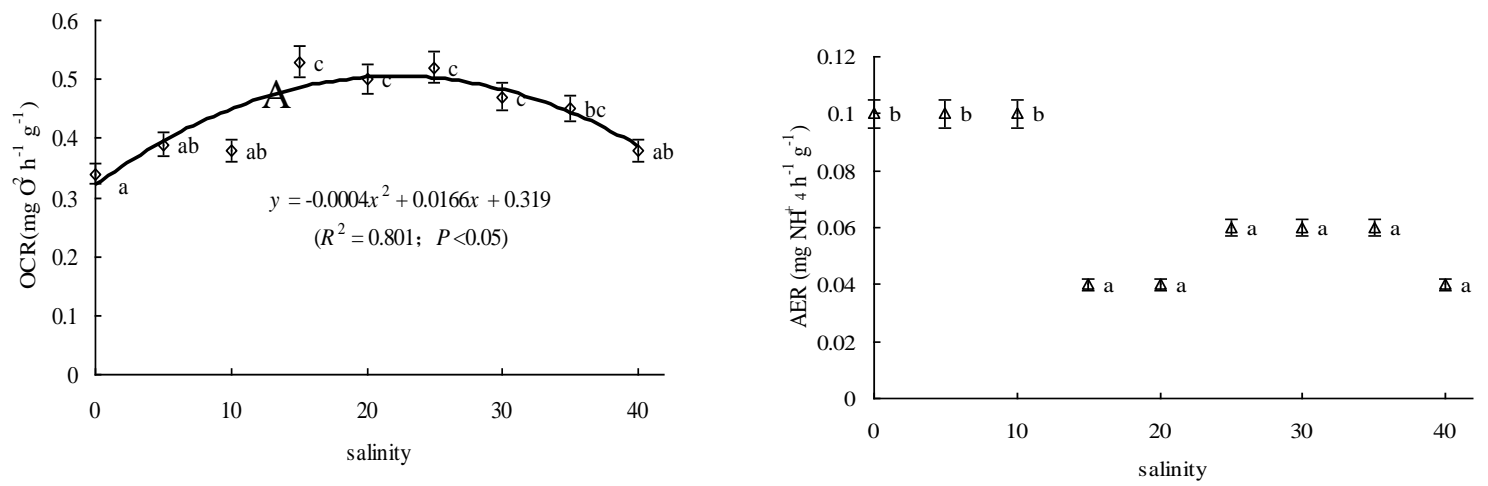

The ammonia excretion rates at $0 \%, 5 \%$, and $10 \%$ salinities were higher than those at the other salinities $(P<0.05)$. And no significant differences on the ammonia excretion rate had been detected at salinities above $15 \%$ o $(P>0.05)$.

Whole body composition

After 40 days, acclimation the influences of salinity on body protein and moisture content were insignificant. There were no significant differences among the treatments $(P>0.05$; table 2$)$. However, the lipid content declined as salinity increased. Lipid content 
was higher at $0 \%$ o than that at $10 \%, 25 \%, 30 \%, 35 \%$, and $40 \%$ o $(P<0.05)$. There were no significant differences of lipid content at $0 \%$, 5\%o, $15 \%$ and $20 \%$ o $(P>0.05)$. Ash content at $5 \%$ o was significantly lower than that at $25 \%$, $35 \%$, and $40 \%$ o $(P<0.05)$. Ash content among other salinities showed no significant differences $(P>0.05)$.

Table 2. Body composition of the American shad A. sapidissima affected by salinities

\begin{tabular}{lllll}
\hline Treatment & Protein $(\%)$ & Lipid (\%) & Ash $(\%)$ & Moisture $(\%)$ \\
\hline 0 & $18.13 \pm 0.82^{\mathrm{x}}$ & $7.14 \pm 1.18^{\mathrm{z}}$ & $2.30 \pm 0.41^{\mathrm{xy}}$ & $71.64 \pm 1.02^{\mathrm{x}}$ \\
5 & $18.66 \pm 0.2^{\mathrm{x}}$ & $6.78 \pm 0.85^{\mathrm{yz}}$ & $2.16 \pm 0.03^{\mathrm{x}}$ & $71.20 \pm 0.15^{\mathrm{x}}$ \\
10 & $18.69 \pm 0.3^{\mathrm{x}}$ & $5.71 \pm 0.58^{\mathrm{x}}$ & $2.38 \pm 0.36^{\mathrm{xy}}$ & $71.70 \pm 0.66^{\mathrm{x}}$ \\
15 & $18.64 \pm 0.2^{\mathrm{x}}$ & $6.15 \pm 0.25^{\mathrm{xyz}}$ & $2.28 \pm 0.50^{\mathrm{xy}}$ & $71.28 \pm 0.4^{\mathrm{x}}$ \\
20 & $18.12 \pm 0.4^{\mathrm{x}}$ & $6.15 \pm 0.26^{\mathrm{xyz}}$ & $2.33 \pm 0.04^{\mathrm{xy}}$ & $72.04 \pm 0.3^{\mathrm{x}}$ \\
25 & $18.40 \pm 0.5^{\mathrm{x}}$ & $5.80 \pm 0.13^{\mathrm{xy}}$ & $2.50 \pm 0.03^{\mathrm{y}}$ & $71.98 \pm 0.2^{\mathrm{x}}$ \\
30 & $18.19 \pm 0.9^{\mathrm{x}}$ & $5.70 \pm 0.86^{\mathrm{x}}$ & $2.33 \pm 0.18^{\mathrm{xy}}$ & $72.38 \pm 1.4^{\mathrm{x}}$ \\
35 & $18.46 \pm 0.2^{\mathrm{x}}$ & $5.63 \pm 0.57^{\mathrm{x}}$ & $2.51 \pm 0.03^{\mathrm{y}}$ & $71.72 \pm 0.6^{\mathrm{x}}$ \\
40 & $17.97 \pm 0.7^{\mathrm{x}}$ & $5.60 \pm 0.41^{\mathrm{x}}$ & $2.54 \pm 0.03^{\mathrm{y}}$ & $72.72 \pm 0.7^{\mathrm{x}}$ \\
\hline
\end{tabular}

\section{Discussion}

It is well known that American shad spawn in freshwater rivers, and a few months after hatching, juveniles start their seaward migration to live in estuarine habitats. The salinity challenge here had a significant effect on the juveniles. Working with 30 day old American shad, a better survival at $10 \%$ than that at $0 \%$ was observed (Limburg \& Ross, 1995). In this study, survival rates at salinities ranging from $5 \%$ to $35 \%$ were better than in the control group (0\%o). This finding confirmed the hypothesis established by Zydlerski and McCormick (1997) who recorded that 24 hours survival at 35\%o was a good indicator of long-term survival in American shad. Moreover, the highest survival rates in data occurred at $5 \%$ and $15 \%$, suggesting the American shad juveniles could adapt to the brackish environment. However, this outcome was opposite to that in another study which showed that the mortality of American shad was markedly high at $20 \%$ and $30 \%$, reaching $100 \%$ (Jia et al. 2009). A possible explanation for this might be the differences in fish size. According to the study on Chinese sturgeons, mortality among fish in brackish water and seawater was inversely associated with their capacity for osmoregelation, which was dependant on fish size (Zhao et al. 2011). In addition, another study found that American shad could not survive a direct transfer from freshwater to salinity 35\% until they were $36 \mathrm{~d}$ post hatching (Zydlewski and McCormick, 1997). There has been a large volume of published literature describing the influence of water salinity on fish growth performance. The best growth of Atlantic cod (Gadus morhua) occurred at 14\%o when tested at 7\%o, 14\%o, and 28\%o (Lambert et al. 2011). The growth of Arctic cisco (Coregonus autumnalis) did not change significantly in salinity ranging from $6 \%$ and $30 \%$ (Fechhelm et al. 1993). When grown in salinities of $15 \%$, 35\%o, and 55\%, milkfish (Chanos chanos) showed optimal growth at 55\%o (Swanson 1998). Apart from survival rates, negative relationships also exist between rising salinity and relative weight gain and specific growth rate in juveniles. In the present study, the values of relative weight gain and specific growth rate significantly decreased as salinity increased. The same result was reported by Jia et al. (2009) in which the highest specific growth rate of the American shad was detected at $0 \%$ and $5 \%$. Nevertheless, there was no better growth performance at salinities ranging from $25 \%$ o to $40 \%$ o, demonstrating that excessively high salinity may adversely affect growth of American shad juveniles. After acclimation to different salinities, feed conversion rate of the experimental fish differed. Our results showed a significant positive relationship between salinity and feed conversion rate. The ratios of feed conversion rate were more efficient in salinity lower than $20 \%$. More efficient conversion ratios resulted in higher growth performance. These results corresponded those in earlier studies which found the higher growth rates could be attributed to the lowered feed conversion rate (Jia et al.2009; Liu et al. 2017). In the present study, the feed conversion rate obtained at $40 \%$ was significantly higher. A possible explanation for this might be changes in gut evacuation rate, caused by fish drinking excess seawater in order to compensate for loss of water to the hyper-osmotic environment (Lambert et al. 2011). Increased body moisture content in the fish was also found (Partridge and Jenkins 2002). This finding 
was supported by higher body moisture content at $40 \%$ in the present study even though it was not significantly higher.

To date, various studies have been carried out to explore the effect of salinity on metabolic and nitrogen excretion rates of marine teleosts (Gracia-Lopez et al. 2006; Zheng et al. 2008). Oxygen uptake and ammonia excretion are indicators to assess energy utilization under stressful environments. However, the results could be speciesspecific. Four types of metabolic responses in aquatic organisms exposed to changes in salinity were found (Kinne, 1967). Data obtained in the present study showed that oxygen consumption was notably influenced by salinity. The oxygen consumption rate of American shad increased significantly with salinity increasing from $0 \%$ to $15 \%$ o but decreased significantly with salinity increasing from $30 \%$ to $40 \%$. No significant differences were detected among $15 \%$ o, 20\%o, 25\%o, and 30\%o salinity. Regression analysis showed a parabolic relationship between oxygen consumption rates in relation to salinity. The peak of oxygen consumption rate appeared at salinity $20.75 \%$ via the quadratic relationship. Oxygen consumption decreased on either side of the optimum corresponding to type 4 defined by Kinne (1967).

Both oxygen consumption rate of American shad, and ammonia excretion rate were affected by salinity. The excretion ratio in this research decreased significantly with salinity which increased from $10 \%$ o to $15 \%$, but no further differences were observed at salinities ranging from $15 \%$ to $40 \%$. Increase in salinity reduced the excretion of ammonia; this may be an indicator of amino acid catabolism decreasing at intermediate salinities (Urbina and Glover 2015). Although this remains to be proven, the reduced production of ammonia may suggest that American shad directs "excess energy" to anabolic processes such as growth. Indeed, this was confirmed in the present study. But, as salinity increased from $25 \%$ to $40 \%$, ammonia excretion rate did not increase significantly. A similar result was found in the bullseye puffer (Sphoeroides annulatus), showing that ammonia excretion rate was not affected by salinity changes (Pérez-Robles et al. 2012). According to the work on Gulf sturgeon Acipenser oxyrinchus desotoi, ammonia excretion decreased significantly with increasing salinity (Altinok and Grizzle 2004). It is difficult to explain these results, although a possible explanation might be the period of acclimation to salinity (Claireaux and Lagardère 1999). According to oxygen consumption rate and ammonia excretion rate trends that changed with salinity, it could be hypothesized that the optimal salinity range for American shad was between $15 \%$ $20 \%$.

In our study, results showed that salinity did not affect body moisture and protein content of American shad via proximate analysis; this is in agreement other studies (Krogdahl et al. 2004). However, body lipid content of American shad decreased with increased salinity, indicating the important role of lipids in osmoregulation of fish (Jarvis and Ballantyne 2003; Gan et al. 2016). No significant effect of salinity on body ash content was detected in our research. A reasonable explanation for this biochemical modulation was that American shad regulate their body composition to survive in hyperosmotic environments (Woo and Tong 2010).

The most obvious finding to emerge from this study was that American shad reared at salinities $5 \%, 10 \%, 15 \%$, and $20 \%$ o had better growth performance and more efficient conversion ratios. $15 \%$ and $20 \%$ salinities were found to conserve energy. We conclude from our results that the most helpful and acceptable salinity for American shad culture ranges from $15 \%$ to $20 \%$. Our results are supported by another study which found that salinity ranging from $14 \%$ to $21 \%$ was considered most acceptable and helpful for American shad culture (Liu et al. 2017). Even though the American shad spawn and grow in freshwater, its culture would be more successful in certain salinity levels to inhibit water mold (Shi et al. 2010; Yan et al. 2004).

\section{Acknowledgements}

This study was supported by the projects as follows: (1) the key research project of Shanghai Municipal Agricultural Commission (2014, NO. 7-1-9); (2) the key scientific and technological research project of Shanghai Municipal Science and Technology Commission (16391900400); (3) the artificial breeding engineering technology research center of major economic aquatic animals in the Yangtse River Estuary in Shanghai (13DZ2251800). 


\section{References}

Altinok, I., and J. M. Grizzle, 2004. Excretion of ammonia and urea by phylogenetically diverse fish species in low salinities. Aquaculture, 238: 499-507.

Andersen, A. K., Schou, J., Sparrevohn, C. R., Nicolajsen, H., and J. G. Støttrup, 2005. The quality of release habitat for reared juvenile flounder, Platichthys flesus, with respect to salinity and depth. Fisheries Management Ecol, 12: 211-219.

$\mathbf{B i}$, Y. H., and X. W. Chen, 2011. Mitochondrial genome of the American shad Alosa sapidissima. Mitochondrial Dna, 22: 9.

Boeuf, G., and P. Payan, 2001. How should salinity influence fish growth? Comp Biochem Physiol Toxicol Pharmacol, 130: 411-423.

Brett, J. R., 1979. Environmental factors and growth. Fish Physiol, 8: 599-675.

Cerezo, V. J., Martínez López, F. J., and G. B. GarcíA, 2006. Oxygen consumption and ventilatory frequency responses to gradual hypoxia in common dentex (Dentex dentex): Basis for suitable oxygen level estimations. Aquaculture, 256: 542-551.

Chang, E. W., Loong, A. M., Wong, W. P., Chew, S. F. , Wilson, J. M. and Y. K. Ip, 2007. Changes in tissue free amino acid contents, branchial $\mathrm{Na}^{+} / \mathrm{K}^{+-}$ATPase activity and bimodal breathing pattern in the freshwater climbing perch, Anabas testudineus (Bloch), during seawater acclimation. J Exp Zool A: Ecol Gen Physiol, 307: 708-723.

Chittenden, M. E., 1973. Salinity tolerance of young American shad, Alosa sapidissima. Chesapeake Science, 14: 207-210.

Claireaux, G., and J. P. Lagardère, 1999. Influence of temperature, oxygen and salinity on the metabolism of the European sea bass. J Sea Res, 42: 157-168.

Fechhelm, R. G., Fitzgerald, P. S., Bryan, J. D. and B. J. Gallaway, 1993. Effect of salinity and temperature on the growth of yearling Arctic cisco (Coregonus autumnalis) of the Alaskan Beaufort Sea. J Fish Biol, 43: 463-474.

Gan, L., Xu, Z. X., Ma, J. J. , Xu, C. , Wang, X. D. , Chen, K. , Chen, L. Q. and E. C. Li, 2016. Effects of salinity on growth, body composition, muscle fatty acid composition, and antioxidant status of juvenile Nile tilapia Oreochromis niloticus (Linnaeus, 1758). J Appl Ichthyol, 32: 372-374.

Gao, X. Q., Liu, Z. F., Guan, C. T., Huang, B. , Lei, J. L., Li, J., Guo, Z. L., Wang, Y. H., and L. Hong, 2017. Developmental changes in digestive enzyme activity in American shad, Alosa sapidissima, during early ontogeny. Fish Physiol Biochem, 43: 307-409.

Gonzalez, R. J., 2012. The physiology of hyper-salinity tolerance in teleost fish: a review. J Comp Physiol B, 182: 321-329.

Gracia-Lopez, V., Rosas-Vazquez, C. and R. Brito-Perez, 2006. Effects of salinity on physiological conditions in juvenile common snook Centropomus undecimalis. Comp Biochem Physiol A Mol Integr Physiol, 145: 340-345.

Hasselman, D. J., Ricard, D. and P. Bentzen, 2013. Genetic diversity and differentiation in a wide-ranging anadromous fish, American shad (Alosa sapidissima), is correlated with latitude. Mol Ecol, 22: 1558-1573.

Hong, X. Y., Zhu, X. P., Chen, K. C., Pan, D. B. and K. B. Li, 2013. Ontogenetic development of the digestive tract in larvae of American shad. North American J Aquacult, 75 : 220-227.

Krogdahl A., Sundby, A. and J. J. Olli, 2004. Atlantic salmon (Salmo salar) and rainbow trout (Oncorhynchus mykiss) digest and metabolize nutrients differently. Effects of water salinity and dietary starch level. Aquaculture, 229:335-360.

Ivančič, I., Degobbis, D., Ivančič, I. and D. Degobbis, 1984. An optimal manual procedure for ammonia analysis in natural waters by the indophenol blue method. Water Res, 18: $1143-1147$.

Jarvis, P. L., and J. S. Ballantyne, 2003. Metabolic responses to salinity acclimation in juvenile shortnose sturgeon Acipenser brevirostrum. Aquaculture, 219: 891-909.

Kinne, O., 1967. Physiology of estuarine organisms with special reference to salinity and temperature: general aspects. Am Assoc Adv Sci Pub.,83: 525-540.

Laiz-Carrion, R., Sangiao-Alvarellos, S., Guzman, J. M., Martin del Rio, M.P., Soengas, J. L., and J. M. Mancera, 2005. Growth performance of gilthead sea bream Sparus aurata in different osmotic conditions: Implications for osmoregulation and energy metabolism. Aquaculture, 250: 849-861. 
Lambert, Y., Dutil, J. D. and J. Munro, 1994. Effects of intermediate and low salinity conditions on growth rate and food conversion of Atlantic Cod (Gadus morhua). Canadian J Fish Aquat Sci, 51: 1569-1576.

Limburg, K. E., and R. M. Ross, 1995. Growth and mortality rates of larval American shad, Alosa sapidissima, at different salinities. Estuaries and Coasts, 18: 335-340.

Liu, Z. F., Gao, X. Q., Yu, J. X., Qian, X. M., Xue, G. P., Zhang, Q. Y., Liu, B. L. and L. Hong, 2017. Effects of different salinities on growth performance, survival, digestive enzyme activity, immune response, and muscle fatty acid composition in juvenile American shad (Alosa sapidissima). Fish Physiol Biochem, 43: 761-773.

Partridge, G. J., and G. I. Jenkins, 2002. The effect of salinity on growth and survival of juvenile black bream (Acanthopagrus butcheri). Aquaculture, 210: 219-230.

Pérez-Robles, J., Re, A. D., Giffard-Mena, I. and F. Díaz, 2012. Interactive effects of salinity on oxygen consumption, ammonium excretion, osmoregulation and $\mathrm{Na}^{+} / \mathrm{K}^{+}$-ATPase expression in the bullseye puffer (Sphoeroides annulatus, Jenyns 1842). Aquacult Res, 43: $1372-1383$.

Plaut, I., 2000. Resting metabolic rate, critical swimming speed, and routine activity of the euryhaline cyprinodontid, Aphanius dispar, acclimated to a wide range of salinities. Physiol Biochem Zool, 73: 590-596.

Shi, Y. H., Zhang, G. Y., Zhu, Y. Z. and J. Z. Liu, 2010. Effects of photoperiod, temperature, and salinity on growth and survival of obscure puffer Takifugu obscurus larvae. Aquaculture, 309: 103-108.

Shi, Y. H., Zhang, G. Y., Liu, J. Z. and W. L. Zang, 2010. Effects of temperature and salinity on oxygen consumption of tawny puffer Takifugu flavidus juvenile. Aquacult Res, 42(2), 301-307.

Sparks, R. T., Shepherd, B. S., Ron, B., Riley, L. G., Iwama, G. K., Hirano, T . and G. E. Gordon, 2004. Effects of environmental salinity and 17a-methyltestosterone on growth and oxygen consumption in the tilapia, Oreochromis mossambicus. Comp Biochem Physiol B Biochem Mol Biol, 136: 657-665.

Swanson, C., 1998. Interactive effects of salinity on metabolic rate, activity, growth and osmoregulation in the euryhaline milkfish (Chanos chanos). J Exp Biol, 201: 3355-3366.

Uliano, E., Cataldi, M., Carella, F., Migliaccio, O., Iaccarino, D. and C. Agnisola, 2010. Effects of acute changes in salinity and temperature on routine metabolism and nitrogen excretion in gambusia (Gambusia affinis) and zebrafish (Danio rerio). Comp Biochem Physiol A Mol Integr Physiol, 157: 283-290.

Urbina, M. A., and C. N. Glover, 2015. Effect of salinity on osmoregulation, metabolism and nitrogen excretion in the amphidromous fish, inanga (Galaxias maculatus). J Exp Mar Biol Ecol, 473: 7-15.

Woo, N. Y. S., and W. C. M. Tong, 1982. Salinity adaptation in the snakehead, Ophiocephalus maculatus Lacepede: changes in oxygen consumption, branchial $\mathrm{Na}+-\mathrm{K}+-$ ATPase and body composition. J Fish Biol, 20: 11-19.

Wright, P. A., Part, P.and C. M. Wood, 1995. Ammonia and urea excretion in the tidepool sculpin (Oligocottus maculosus): sites of excretion, effects of reduced salinity and mechanisms of urea transport. Fish Physiol Biochem, 14: 111.

Wuenschel, M. J., Jugovich, A. R. and J. A. Hare, 2005. Metabolic response of juvenile gray snapper (Lutjanus griseus) to temperature and salinity: Physiological cost of different environments. J Exp Mar Biol Ecol, 321: 145-154.

Yan, M., Li, Z., Xiong, B. and J. Zhu, 2004. Effects of salinity on food intake, growth, and survival of pufferfish (Fugu obscurus). J Appl Ichthyol, 20: 146-149.

Jia Y. J., Liu, Q. H., Goudie, C. A. and B. A. Simco, 2009. Survival, Growth, and Feed Utilization of Pre- and Postmetamorphic American Shad Exposed to Increasing Salinity, North American J Aquacult, 71:3, 197-205

Zhao F., Qu, L., Zhuang, P., Zhang, L., Liu, J. and T. Zhang, 2011. Salinity tolerance as well as osmotic and ionic regulation in juvenile Chinese sturgeon (Acipenser sinensis Gray, 1835) exposed to different salinities. J Appl Ichthyol, 2011, 27(2):231-234.

Zheng, Z., Jin, C., Li, M., Bai, P., and S. Dong, 2008. Effects of temperature and salinity on oxygen consumption and ammonia excretion of juvenile miiuy croaker, Miichthys miiuy (Basilewsky). Aquacult Int, 16: 581-589.

Zydlewski, J., and S. D. McCormick, 1997. The ontogeny of salinity tolerance in the American shad, Alosa sapidissima. Canadian J Fish Aquat Sci, 54: 182-189. 